\title{
Barriers to and facilitators of adherence to exclusive breastfeeding practices among HIV infected and non-infected women in Jos, Nigeria
}

\author{
Bronwynè Coetzee $^{1}$, Mark Tomlinson ${ }^{1}$, Sophia Osawe², Alash'le Amibiku², Ashraf Kagee, \\ and the INFANT study team \\ ${ }^{1}$ Department of Psychology, Stellenbosch University, South Africa \\ 2Plateau State Human Virology Research Center (PLASVIREC), Jos, Nigeria
}

\section{Abstract}

Objectives-In Nigeria adherence to exclusive breastfeeding (EBF) practices is currently suboptimal and a better understanding of the factors affecting adherence to EBF is needed. We sought to identify and delineate the barriers to and facilitators of adherence to EBF amongst HIVinfected and uninfected women in Nigeria.

Methods-We explored the barriers and facilitators to EBF amongst 37 (25 HIV-infected and 12 HIV-uninfected) pregnant women attending an antenatal clinic in Jos, Nigeria. In-depth interviews were conducted with each of the pregnant women in their third trimester of pregnancy and again one month after giving birth.

Results-The themes that emerged were mothers' feeding intentions, significant role players in the decision to breastfeed, perceived barriers (e.g. physiological issues, stigma, employment) and perceived facilitators (e.g. pleasure and enjoyment derived from breastfeeding, natural milk from God, disclosure and family support) associated with EBF.

Conclusions-Most women preferred EBF and offered it to their infants. However, more efforts are needed to improve support structures at home and at work to accommodate women who choose to do EBF.

\section{Keywords}

exclusive breastfeeding; barriers; facilitators; Nigeria; HIV

\section{Introduction}

As a way to prevent mother to child transmission of HIV during the post-partum period, the World Health Organisation (WHO) and the United Nations Children's Fund (UNICEF) recommend exclusive breastfeeding (EBF) for the first six months of an infant's life.

Corresponding author: Bronwynè Coetzee, Department of Psychology, Stellenbosch University, Private Bag X1, Matieland, 7602, South Africa, bronwyne@sun.ac.za. 
Thereafter, breastfeeding is recommended for at least two years with complimentary foods introduced after six months (World Health Organization, 2010).

In the absence of antiretroviral treatment (ART), vertical transmission via breastfeeding contributes substantially to HIV infection in children (Kourtis, Lee, Abrams, Jamieson, \& Bulterys, 2006; Volmink \& Marais, 2008). Despite the risk of HIV transmission via breastfeeding, EBF significantly reduces the risk of HIV transmission to infants compared to mixed feeding (supplementing breastfeeding with other liquids and foods) (Buskens, Jaffe, \& Mkhatshwa, 2007; Coovadia et al., 2007; Doherty, Sanders, Goga, \& Jackson, 2011; Iliff et al., 2005). Evidence from large prospective studies conducted in sub-Saharan Africa have shown a two- to 11-fold reduction in MTCT among HIV infected women who exclusively breast feed compared to those who mix feed (Coovadia et al., 2007; Coutsoudis, Pillay, Spooner, Kuhn, \& Coovadia, 1999; Iliff et al., 2005; Kuhn et al., 2007). Long-term benefits of breastfeeding include a reduction in infant morbidity and mortality (Ip et al., 2007), improved growth and development of the child, and improved cognitive development and educational attainment (Horta \& Victora, 2013; Kramer et al., 2008; Lucas, Morley, Cole, Lister, \& Leeson-Payne, 1992; Victora et al., 2015).

Despite the benefits associated with breastfeeding, adherence to EBF and sustained breastfeeding practices remain low, with an estimated $38 \%$ of infants receiving EBF for the first 4 months of life (World Health Organization, 2015). Nigeria introduced the Baby Friendly Hospital Initiative (BFHI) in 1992 in line with global guidelines and recommendations (Aidam, Pérez-Escamilla, \& Lartey, 2005; T.A. Ogunlesi, Dedeke, Okeniyi, \& Oyedeji, 2005). Following the introduction of the BFHI, early initiation of BF improved by 33\% (National Population Commission (NPC) [Nigeria] and ICF Macro, 2013). Despite the increased uptake of BF practices, adherence to EBF remains too low at $17 \%$ to significantly reduce childhood mortality rates (Agho, Dibley, Odiase, \& Ogbonmwan, 2011; Ogbo, Agho, \& Page, 2015; Tinuade A. Ogunlesi, 2010).

Although adherence to breastfeeding at one year is higher in Nigeria (84\%) (NPC, 2013) than in the United States (26\%) (Center for Disease Control, 2012), the prevalence of EBF in Nigeria (17\%) remains lower compared to other sub-Saharan African countries like Tanzania (50\%) (Victor, Baines, Agho, \& Dibley, 2013), Burkina Faso (77\%) (Goga, Dinh, \& Jackson, 2012) and Kenya (32\%) (Kenya National Bureau of Statistics, MEASURE DHS and ICF Macro, 2010). Data from the Nigerian Demographic and Health Survey (2008) show that only $20 \%$ of women engage in EBF from the birth of their child and just over 35\% of women supplement with non-milk liquids, other milk or formula very early age in the child's life (National Population Commission (NPC) [Nigeria] and ICF-Macro, 2013). Thus, most children under six months in Nigeria receive complimentary foods or liquids when breastfed (Ogbo et al., 2015). Current EBF rates in Nigeria are estimated at approximately $13 \%$ after six months of age (Joint United Nations Programme on HIV/AIDS, 2010).

Socio-demographic, maternal and health-care related factors may impact breastfeeding practices (Balogun et al., 2015; Buskens et al., 2007). At an individual level, mothers may have concerns about milk production and whether the infant is receiving enough food. Further, low rates of disclosure to family members due to HIV related stigmatisation and 
discrimination has been shown to negatively impact EBF (Maru et al., 2009; Moland et al., 2010). Health care workers may also negatively impact EBF practices, especially if they are not convinced of the efficacy of EBF and therefore recommend formula feeding to mothers (Buskens et al., 2007; Sibeko, Coutsoudis, Nzuza, \& Gray-Donald, 2009). At a cultural level, mothers who do not follow traditional norms risk exclusion by family members. It has been found that older women, especially grandmothers, often encourage the introduction of liquids and traditional foods in infant-feeding (Bezner Kerr, Dakishoni, Shumba, Msachi, \& Chirwa, 2008), practices that strongly contradict medical advice (Fjeld et al., 2008). The low uptake of EBF in Nigeria brings into focus the need to understand the barriers and facilitators to this potentially life-saving practice in the context of HIV infected women with uninfected infants.

In this study we used an ecological health paradigm to frame our conceptualisation of factors influencing infant feeding methods (Glanz, Rimer, \& Viswanath, 2008). The ecological health paradigm considers both the individual and their environment as equal determinants for achieving health success in the face of multiple levels of influence of various interacting and dynamic systems.

\section{Methods}

\section{Study setting}

The study was conducted at Plateau State Specialist Hospital (PSSH), in Jos, in the north central region of Nigeria by PLASVIREC staff. PSSH is a 170-bed community based hospital in the city of Jos, the capital of Plateau State with a population of about 700000 , and an HIV prevalence of 16.7\% (CI:12.4-20.9) (Federal Ministry of Health Nigeria, 2010). In addition, PSSH is also a referral center for several satellite antenatal clinics that cater to more rural women within Plateau State.

\section{Sampling}

We used purposive sampling methods to select and invite two groups of pregnant women attending the antenatal clinic at PSSH who met the following criteria to participate in the study: HIV infected and uninfected women over 18 years, in their third trimester of pregnancy.

\section{Procedure}

We interviewed 25 HIV infected and 12 HIV uninfected women at two time points. The first time point was during women's third trimester of pregnancy, while the second time point was one to three months post-delivery (depending on availability and convenience). The interview sessions at both time points consisted of largely the same interview questions and responses were similar. Enrolment took place twice a week, on Mondays and Fridays as these were the days when new bookings of pregnant women took place at the antenatal clinic. Interviews took place in a private room near the antenatal clinic at PLASVIREC. Interviews lasted up to an hour, were audio recorded, and transcribed verbatim. Interviews conducted in Hausa (local language), were translated into English. 


\section{Data Analysis}

We used thematic analytic procedures to analyze the transcripts (Braun \& Clarke, 2006). Thus, English transcripts were read several times before being imported into a computer assisted qualitative data analysis software programme (CAQDAS). Initial reading of the transcripts allowed for familiarization with the data and the establishment of a preliminary set of codes. The preliminary set of codes resembled semantic codes which developed into latent codes through merging and grouping relevant codes into broader themes. We used ATLAS.ti version 7 (www.atlasti.com) to manage and code the transcripts thematically. Following initial coding of all transcripts they were grouped into two groups to reflect the sampling criteria, and compared for similarities and differences. Participant names have been changed and pseudonyms are used throughout the manuscript.

\section{Ethics}

The study received ethical clearance from the Health Research Ethics Committee at Stellenbosch University (N12/05/021) as well as from the Institutional Review Board (IRB) at the PSSH in Jos, Nigeria. Following a detailed explanation of the protocol, in which participants were assured of anonymity and confidentiality of the data, all participants provided written informed consent. Further, all participants received free transportation to and from the assessment location.

\section{Results}

As can be seen from Table 1, our final sample consisted of 25 HIV infected women, and 12 HIV uninfected women, in their third trimester of pregnancy recruited from the antenatal clinic. At recruitment, HIV infected women had a median age of 33, whereas HIV uninfected women had a median age of 30. The majority of HIV infected (15 out of 25) and HIV uninfected women ( 8 out of 12) were pregnant with either their first or second child. Most (17 out 25) of the HIV infected women had secondary school education or higher. Nearly all of the HIV uninfected women had received higher education. Most of the HIV infected (11 out of 25) and HIV uninfected women (6 out of 12) were self-employed. Nearly all (35 out of 37) of the women were married. Most (34 out of 37) of the women had access to electricity. However not all had access to a refrigerator (20 out of 37 ) or running water (12 out of 37).

\section{Themes}

Table 2 provides an overview of the themes and sub-themes that emerged from the thematic analysis. Taken together these may be grouped under three overarching themes representing the key factors important to Nigerian mothers' decisions on feeding methods and factors influencing these practices

1. Influences on feeding method decisions

2. Factors (barriers and facilitators) influencing feeding intentions

3. Support structures 


\section{Influences on feeding method decisions}

Participants were unanimous about their intentions to exclusively breastfeed their infants at interview 1, and all had stated that they were EBF their infants at interview 2. Their decision to EBF was based on information they had received from the healthcare staff at the antenatal clinic, as well as input from their husbands and other family members and friends. This information, along with their own knowledge and beliefs about the benefits of EBF, were the most salient factors in determining method of feeding. Participants were educated by healthcare workers about EBF and the benefits thereof, and most women were comfortably able to recall this information. As Linda stated:

As I am living with HIV, they teach us, if you are taking the drugs, nothing will temper (be wrong) with your child, but if you are not taking the drugs, your child will be infected, but once you are taking the drugs, there is nothing will temper with your child, because the drugs that the mother is taking it, as I am taking it, will protect my child. [P56 - HIV infected women expecting her second child]

Participants described the information on EBF as clear and informative. However for one participant conflicting messages from heath care workers meant that she was unsure as to how long she should engage in EBF. Sarah stated:

I had a little challenges with some health workers too. It was only the doctor that was advising me positively. Some of the workers were like this...the...the...don't mind the doctor, if you must breastfeed your baby it should be like 3 months and that should be ok, that it shouldn't go beyond that, that you are putting your baby on a higher risk of contracting the disease. [P15- HIV infected women pregnant with her second child]

Many of the HIV infected participants had only disclosed their statuses to their husbands, and in a few instances to their mothers and/or a sibling. For both HIV infected and uninfected women, husbands were identified as key consultants when deciding about infant feeding practices. As Joss stated: "Because... I keep my secret between me and my husband". [P58- HIV infected women pregnant with her third child]

Thus, decisions about the mode of infant feeding were mainly discussed between the participant and her husband. Most participants said their husbands were satisfied with the clinician recommendations of EBF.

Maternal knowledge and beliefs about EBF-Participants' own knowledge and beliefs about EBF also influenced their decision. Several women were able to draw on their own experiences in previous pregnancies, from observations of other women in their families, and from those that they had met at the clinic whose children they had seen in informing their decision to breast feed. For example, several participants stated that they had seen the positive growth effects and lack of infant illnesses associated with EBF either in their own children that had received EBF in the past, or the children of other women (family or friends) who had received EBF. As Thelma, a stay at home mother stated, "I have two friends that do the (exclusive breastfeeding) and they advised me that it's very good... I saw the children are healthy". [P50-HIV uninfected and pregnant with first child] 
Participants stated that EBF for their children meant cognitive development of their children who were healthier and grew more than formula fed or mixed fed children. Although both HIV infected and non-infected women were determined to EBF their new born infants, many anticipated barriers and facilitators to this practice.

\section{Factors influencing feeding intentions}

Physical problems (nipple pain, and milk expression)—Both HIV infected and uninfected mothers expressed an overwhelming desire to EBF their infants. The majority of the HIV infected women had been negative in previous pregnancies. Breastfeeding was still the predominant mode of feeding used within previous pregnancies but was often changed to mixed feeding practices within the first 4 months. Respondents stated that nipple pain and the inability to express enough milk for the infant were some of the factors that forced them to introduce alternative foods earlier than anticipated in previous pregnancies. As Sarah, stated:

It's not that I don't like to continue but it's due to the problem that I encountered myself, I was not be able to get milk for the, the baby did not be.......she did not get the milk the way she like then. [P7- HIV infected mother pregnant with her $2^{\text {nd }}$ child]

At interview 2, seven HIV infected women stated that nipple pain was problematic for them largely during the first two week of breastfeeding. The pain for most of these women subsided and did not result in them resorting to other feeding methods.

Teething-Despite a clear knowledge of the benefits associated with EBF, participants were worried about whether they would be able to remain adherent to EBF for a full six months. More than half of the HIV infected women reported that they would only EBF for the six months after which they would stop breastfeeding all together and introduce other foods. They expressed concern about transmitting HIV to their new born via bleeding nipples as a result of infant teething. When asked about why they would stop all together, the women reported that this is what they understood from the information given to them by the healthcare staff and that it had to do with infant teething and bleeding nipples. As Sarah, stated:

Because you know they say that it is not good for us to continue because maybe during sometimes the baby will start having teeth then the baby will start biting, at the process of giving that breastfeeding the baby will bite the nipples and blood will come out from there the baby will... will take the infection so I don't want a situation whereby my baby will be infected with the virus. [P7]

Another respondent at interview 2 stated:

When I met the doctor, she told me that once the baby start removing teeth is dangerous because the baby will be biting you so...they don't want wound, they don't want the baby to injure the breast so that the water coming from your body or blood may affect the baby. [P32- HIV infected mother pregnant 1 month after birth] 
Employment-Many of the participants stated that attending work or school would not influence their ability to EBF at interview 1 . They stated that they would either take the infant with them to work or express milk. However, at interview 2 some women stated that EBF posed some challenges as they tried to juggle both work and breastfeeding. For example, long work hours prevented some participants from finding time to go home during the day to feed their child. One participant stated that she did not trust that those at home with the child during the day and was careful and consistent with feeding her child during the day. As Tracy stated:

Yes. When I was doing the exclusive, the babies were healthier than when I was mixing. You know when you mix as a working class mother at times you leave them with children and they won't take care of the containers...At times it may cause... you know dysentery all those things to the baby so the baby may not (be) as healthy as the one you are taking care of and breastfeeding exclusively yourself. [P21- HIV uninfected women pregnant with her fourth child]

Participants were for the most part unaware of the benefits associated with formula feeding a child. However, they associated formula feeding with greater flexibility for a full time working mother. As Alexa, an HIV infected mother pregnant with her $2^{\text {nd }}$ child stated: "The only good thing to the mother is that you have... you will go freely around, you don't have to think of the baby, you don't have to carry the baby all around and that's all I think..." [P15].

Financial security-As most of the participants were unemployed, breastfeeding was considered the better option financially whereas formula feeding was considered expensive and difficult under poor environmental circumstances such as an inability to access clean water, and a lack of sanitary practices when preparing feeding bottles. Further, for many of the women's husbands their decision on EBF was largely based on the affordability of the method versus formula feeding. As Rita stated:

R: In a nutshell, I will say that exclusive breastfeeding is very nice, is more economical that's you are not there to be buying all this uh...formula food which is expensive and then your baby will be healthy for you. [P18- HIV uninfected and pregnant with fourth child]

Stigma-Several HIV infected as well as HIV uninfected women stated that although the information they had received from the clinic was sufficient at convincing them of the benefits of EBF, many still received conflicting messages from some members of their family and other relations. These messages typically reflected negative attitudes towards breastfeeding among HIV infected women - a fear that the virus would be transmitted via the breast milk. As Martha stated:

Yes. Like my mother. The first child, she say that no oh we should not breast feed the baby for too long because she don't want the baby to. catch the virus.

(P7- HIV infected women pregnant with her second child)

Several HIV infected women referred to HIV as "this thing", or "this problem". The inability to name their condition as HIV was testament to the stigma that persons living with HIV still experience. As Genevieve stated: 
You know we are in Nigeria so why am saying that we are in Nigeria is that when somebody is HIV infected, is a like kai!! This person has committed atrocity so people may be afraid of that person talk more of when the person is breastfeeding a baby, so at times they will tell the woman not to breastfeed that child because the child may contact the HIV from the breast...(P34- an HIV uninfected women pregnant with her $4^{\text {th }}$ child).

Both HIV infected and non-infected women were grateful for the opportunity to breastfeed their babies rather than being associated with formula feeding with a fear of being identified by others as infected with HIV.

Cultural beliefs and tradition-Many of the women were aware of certain cultural beliefs held by individuals in their community. However none stated that these necessarily influenced their intended method of infant feeding at interview 1. Typical cultural beliefs that acted as potential barriers held by family members, friends and neighbours were that: (1) infants need water for thirst and hunger, and (2) that HIV infected women's breast milk is bad. As Linda stated:

...like I heard a woman that you are saying that she if she deliver her baby, the children use to die, so they were complaining that it was because of breast...[I: Ok] ...that her breast milk was not good. People were advising her to stop giving the baby breast milk so you understand? So that they will stay according to them. [P20HIV uninfected women pregnant with her second child]

At interview 2 both HIV infected and uninfected women stated that several of their female family members and friends regularly insisted that they supplement the child's feeding with water as they were convinced that the child is thirsty. Despite their insistence women remained determined not to take their advice.

Less commonly reported but nonetheless noteworthy was that (3) HIV infected women's tears taint the breast milk, and (4) the "first milk" is bad for the baby. As Laura stated:

They said they yellowish content there is not good for the baby so they have to extract the breast milk and throw it while they feed the baby on the whitish part". [P8- HIV infected women pregnant with her fourth child]

Other cultural beliefs that acted as potential facilitators were that (1) breastfeeding is a traditional practice and thus favoured, and (2) breast milk is a natural gift from God. Breastfeeding was considered by several women as a religious privilege as they were able to provide their infants with the "natural milk from God" and therefore the best possible food that can be given. As Rose stated:

I didn't see anything there and after all milks are very very expensive now. It's not everybody that can afford it and what you cannot start and end. It's better you don't even start it. So to me oh! I think is the most important thing for me to breastfeed my baby with my breast that God has given me. [P10- HIV infected mother pregnant with her first child] 


\section{Support structures}

Husbands were in many instances women's' only confidant and thus also their largest source of support, both financially and emotionally. Women reported that their husbands assisted them financially, while mothers and sisters were more likely to assist with child care and household chores.

\section{Discussion}

In this study we aimed to better understand the barriers to and facilitators of exclusive breastfeeding practices amongst pregnant Nigerian women attending an antenatal clinic. While there is a substantial literature on the short and long term benefits associated with EBF, less is known about the factors influencing EBF especially the multiple levels on which these factors operate. In this study we have attempted to identify and delineate these factors. In doing so we were able to highlight (1) key consultants in women's decision making process regarding optimal/ preferred feeding methods, (2) important information regarding maternal knowledge and beliefs about EBF, (3), individual and interpersonal factors that influence adherence to EBF, and (4) support structures available to these women in order to mitigate the potential barriers that threaten EBF practices. Additionally, we considered the factors influencing breastfeeding from the perspectives of both HIV infected and uninfected women. To this extent, perceived and experienced individual as well as cultural factors influencing EBF could be compared between the two groups, an important criterion necessary to establish trustworthiness and rigour in qualitative research (Willig \& Stainton-Rogers, 2007).

\section{Influences on feeding method decisions}

Our findings show that the information provided to pregnant women attending the antenatal clinic in Jos was sufficient to convince them to EBF as well as provide them with a good knowledge of the requirements for EBF. These findings are in line with other studies in Africa showing that a basic education on EBF enhanced optimal feeding practices (Otoo, Lartey, \& Pérez-Escamilla, 2009; Tamiru, Belachew, Loha, \& Mohammed, 2012; Tomlinson et al., 2014). Beyond the clinic, our findings showed that women turn to their husbands first as key consultants regarding the preferred method of infant feeding. Other influences on decision making were based on previous experiences with EBF and seeing the healthy children of other women who had used EBF.

Although women in our study indicated an intention to EBF their unborn infants, they shared several concerns about the ability to sustain the practices for the full six months. Women's concerns were related to physical difficulties such as the inability to express enough milk and nipple pain. Perceptions of insufficient breast milk and breast pain are commonly reported as perceived barriers to EBF in the literature (Otoo et al., 2009; Tamiru et al., 2012). Participants reported that they would cease breastfeeding immediately when the infants began teething out of fear that the virus may be transferred to the child via bleeding nipples. 
Participants for the most part had very little knowledge of the benefits of formula feeding. However, they acknowledged that it allowed for more flexibility, especially in the case of working mothers employed full time. In a recent systematic review (Balogun et al., 2015), the influence of work was amongst the most important factors influencing maternal feeding decisions. For example, a sample of Sri Lankan mothers returning to work following delivery ceased EBF as early as 2 months of infant age (Perera, Ranathunga, Fernando, Sampath, \& Samaranayake, 2012). In our study, women stated that full time work did not allow for sufficient time to feed their infants, and that some did not trust others to administer expressed milk to their infants hygienically. Despite relatively little knowledge on formula feeding, women in our study acknowledged that there is still a pervasive stigma attached to using feeding methods other than breastfeeding infants.

Cultural beliefs did not present as a barrier to EBF for women in this study. In fact several women were happy to breastfeed their infants as they were able to keep to traditional feeding modes, and viewed breastfeeding as a religious privilege. However, some indicated that others, such as family member and friends, were likely to advise them to introduce water to their infants as breast milk was not considered sufficient and that children needed water to quench their thirst. The belief that infants require water in addition to the breast milk is frequently reported in the literature. Some studies have showed that women believe that water is needed to aid digestion (Arusei, Ettyang, \& Esamai, 2011), while others believe that water prepares the infant for other foods (Otoo et al., 2009).

Support structures-The majority of women in our study were married, and maternal disclosure of HIV to status to others (family, friends, and neighbours) was uncommon. Husbands thus provided women with a valuable source of support both emotionally and financially. Further, husbands mostly agreed with the decision to EBF child and also viewed this as the best option financially. Our findings contradict those of other studies that have shown husbands to act as potential barriers to EBF. For example, amongst nurses, mother and grandmothers in Nigeria, research showed that inadequate support from husbands and conflicting opinions on feeding methods from significant others were amongst the salient barriers to EBF (Agunbiade \& Ogunleye, 2012).

Limitations-The sample size was small and thus the findings cannot be generalised. However, the findings are transferable to the community of HIV infected and uninfected women attending the antenatal clinic.

Conclusions-In this study we were able to determine the influences on feeding intentions amongst HIV infected and uninfected women attending an ANC in Nigeria. Our findings demonstrate the need for several educational and structural solutions to the barriers influencing adherence to EBF. For example, although women demonstrated a good knowledge of what EBF is and entails more information is needed to address their fears regarding vertical transmission of HIV. Further, more efforts are needed to include husbands and extended family members into antenatal education sessions to deter concerns surrounding infant thirst and the need to supplement EBF with water. Working women require facilities at work to express and refrigerate milk so that they are able to administer it themselves. Day care facilities closer to their place of work may provide additional support. 


\section{References}

Agho KE, Dibley MJ, Odiase JI, Ogbonmwan SM. Determinants of exclusive breastfeeding in Nigeria. BMC Pregnancy and Childbirth. 2011; 11(1):2.doi: 10.1186/1471-2393-11-2 [PubMed: 21219659]

Agunbiade OM, Ogunleye OV. Constraints to exclusive breastfeeding practice among breastfeeding mothers in Southwest Nigeria: implications for scaling up. International Breastfeeding Journal. 2012; 7:5.doi: 10.1186/1746-4358-7-5 [PubMed: 22524566]

Aidam BA, Pérez-Escamilla R, Lartey A. Lactation counseling increases exclusive breast-feeding rates in Ghana. The Journal of nutrition. 2005; 135

Arusei RJ, Ettyang GA, Esamai F. Feeding patterns and growth of term infants in Eldoret, Kenya. Food and Nutrition Bulletin. 2011; 32(4):307-14. Retrieved from http://www.ncbi.nlm.nih.gov/pubmed/ 22590963. [PubMed: 22590963]

Balogun OO, Kobayashi S, Anigo KM, Ota E, Asakura K, Sasaki S. Factors Influencing Exclusive Breastfeeding in Early Infancy: A Prospective Study in North Central Nigeria. Maternal and Child Health Journal. 2015.

Bezner Kerr R, Dakishoni L, Shumba L, Msachi R, Chirwa M. "We Grandmothers Know Plenty": Breastfeeding, complementary feeding and the multifaceted role of grandmothers in Malawi. Social Science \& Medicine. 2008; 66(5):1095-1105. DOI: 10.1016/j.socscimed.2007.11.019 [PubMed: 18155334]

Braun V, Clarke V. Using thematic analysis in psychology. Qualitative Research in Psychology. 2006; 3(2):77-101. DOI: 10.1191/1478088706qp063oa

Buskens I, Jaffe A, Mkhatshwa H. Infant feeding practices: realities and mind sets of mothers in Southern Africa. AIDS Care. 2007; 19(9):1101-1109. DOI: 10.1080/09540120701336400 [PubMed: 18058394]

Centers for Disease Control. Breastfeeding Report Card 2012, United States: outcome indicators. Atlanta, USA: 2012. Retrieved from http://www.cdc.gov/breastfeeding/pdf/ 2012BreastfeedingReportCard.pdf

Coovadia HM, Rollins NC, Bland RM, Little K, Coutsoudis A, Bennish ML, Newell ML. Mother-tochild transmission of HIV-1 infection during exclusive breastfeeding in the first 6 months of life: an intervention cohort study. Lancet. 2007; 369(9567):1107-1116. DOI: 10.1016/ S0140-6736(07)60283-9 [PubMed: 17398310]

Coutsoudis A, Pillay K, Spooner E, Kuhn L, Coovadia HM. Influence of infant-feeding patterns on early mother-to-child transmission of HIV-1 in Durban, South Africa: a prospective cohort study. South African Vitamin A Study Group. Lancet. 1999; 354(9177):471-476. DOI: 10.1016/ S0140-6736\%2899\%2901101-0 [PubMed: 10465172]

Doherty T, Sanders D, Goga A, Jackson D. Implications of the new WHO guidelines on HIV and infant feeding for child survival in South Africa. Bulletin of the World Health Organization. 2011; 89(1):62-67. DOI: 10.2471/BLT.10.079798 [PubMed: 21346892]

Federal Ministry of Health Nigeria. Technical Report on the 2010 National HIV Sentinel Survey among pregnant Women attending Antenatal Clinics in Nigeria. 2010. Retrieved from http:// www.nigeriaaids.org/documents/2010_National HIV Sero Prevalence Sentinel Survey.pdf

Fjeld E, Siziya S, Katepa-Bwalya M, Kankasa C, Moland KM, Tylleskar T. "No sister, the breast alone is not enough for my baby" A qualitative assessment of potentials and barriers in the promotion of exclusive breastfeeding in southern Zambia. International Breastfeeding Journal. 2008; 3(1): 26.doi: 10.1186/1746-4358-3-26 [PubMed: 18986539]

Glanz K, Rimer BK, Viswanath K. HEALTH BEHAVIOR AND HEALTH EDUCATION Theory, Research, and Practice. 4. Orleans T, editorSan Franciso, CA: Jossey-Bass A Wiley; 2008. Imprint

Goga A, Dinh T, Jackson D. effectiveness of the national prevention of mother-to-child transmission (PMTCT) programme on infant HIV measured at six weeks postpartum in South Africa. 2012. Retrieved from http://repository.uwc.ac.za/xmlui/handle/10566/462

Horta B, Victora C. Long-term effects of breastfeeding: a systematic review. Geneva: 2013.

Iliff PJ, Piwoz EG, Tavengwa NV, Zunguza CD, Marinda ET, Nathoo KJ, Humphrey JH. Early exclusive breastfeeding reduces the risk of postnatal HIV-1 transmission and increases HIV-free 
survival. AIDS (London, England). 2005; 19(7):699-708. DOI: 10.1097/01.aids. 0000166093.16446.c9

Ip S, Chung M, Raman G, Chew P, Magula N, DeVine D, Lau J. Breastfeeding and maternal and infant health outcomes in developed countries. Evidence Report/technology Assessment. 2007; (153):1186.

Joint United Nations Programme on HIV/AIDS. UNAIDS REPORT ON THE GLOBAL AIDS EPIDEMIC |. WHO Library Cataloguing-in-Publication Data, 6-8. 2010. Retrieved from http:// www.unaids.org/documents/20101123_globalreport_em.pdf

Kenya National Bureau of Statistics MEASURE DHS and ICF Macro. Kenya Demographic and Health Survey, 2008-09. Calverton, Maryland, USA: 2010. Retrieved from http:// dhsprogram.com/pubs/pdf/fr229/fr229.pdf

Kourtis AP, Lee FK, Abrams EJ, Jamieson DJ, Bulterys M. Mother-to-child transmission of HIV-1: timing and implications for prevention. The Lancet. Infectious Diseases. 2006; 6(11):726-32. DOI: 10.1016/S1473-3099(06)70629-6 [PubMed: 17067921]

Kramer MS, Aboud F, Mironova E, Vanilovich I, Platt RW, Matush L, Shapiro S. Breastfeeding and child cognitive development: new evidence from a large randomized trial. Archives of General Psychiatry. 2008; 65(5):578-584. DOI: 10.1001/archpsyc.65.5.578 [PubMed: 18458209]

Kuhn L, Sinkala M, Kankasa C, Semrau K, Kasonde P, Scott N, Thea DM. High uptake of exclusive breastfeeding and reduced early post-natal HIV transmission. PLoS ONE. 2007; 2(12)doi: 10.1371/journal.pone.0001363

Lucas A, Morley R, Cole TJ, Lister G, Leeson-Payne C. Breast milk and subsequent intelligence quotient in children born preterm. Lancet. 1992; 339(8788):261-264. DOI: 10.1016/0140-6736(92)91329-7 [PubMed: 1346280]

Maru S, Datong P, Selleng D, Mang E, Inyang B, Ajene A, Abimiku A. Social determinants of mixed feeding behavior among HIV-infected mothers in Jos, Nigeria. AIDS Care. 2009; 21(9):11141123. DOI: 10.1080/09540120802705842 [PubMed: 20024770]

Moland K, de Paoli MM, Sellen DW, van Esterik P, Leshabari SC, Blystad A. Breastfeeding and HIV: experiences from a decade of prevention of postnatal HIV transmission in sub-Saharan Africa. International Breastfeeding Journal. 2010; 5(1):10.doi: 10.1186/1746-4358-5-10 [PubMed: 20977709]

National Population Commission (NPC) [Nigeria] and ICF-Macro. Nigeria Demographic and Health Survey 2013. Calverton, Maryland, USA: 2013. Retrieved from http://www.population.gov.ng/ index.php/2013-nigeria-demographic-and-health-survey

Ogbo FA, Agho KE, Page A. Determinants of suboptimal breastfeeding practices in Nigeria: evidence from the 2008 demographic and health survey. BMC Public Health. 2015; 15(1):259.doi: 10.1186/ s12889-015-1595-7 [PubMed: 25849731]

Ogunlesi TA. Maternal socio-demographic factors influencing the initiation and exclusivity of breastfeeding in a Nigerian semi-urban setting. Maternal and Child Health Journal. 2010; 14(3): 459-465. DOI: 10.1007/s10995-008-0440-3 [PubMed: 19156508]

Ogunlesi TA, Dedeke IOF, Okeniyi JAO, Oyedeji GA. The impact of th baby friendly hospital initiative on breastfeeding practices in Ilesa. Nigerian Journal of Paediatrics. 2005; 32(3):46-51.

Otoo GE, Lartey AA, Pérez-Escamilla R. Perceived incentives and barriers to exclusive breastfeeding among periurban Ghanaian women. Journal of Human Lactation : Official Journal of International Lactation Consultant Association. 2009; 25(1):34-41. DOI: 10.1177/0890334408325072 [PubMed: 18971507]

Perera PJ, Ranathunga N, Fernando MP, Sampath W, Samaranayake GB. Actual exclusive breastfeeding rates and determinants among a cohort of children living in Gampaha district Sri Lanka: A prospective observational study. International Breastfeeding Journal. 2012; 7(1):21.doi: 10.1186/1746-4358-7-21 [PubMed: 23259860]

Sibeko L, Coutsoudis A, Nzuza S, Gray-Donald K. Mothers' infant feeding experiences: constraints and supports for optimal feeding in an HIV-impacted urban community in South Africa. Public Health Nutrition. 2009; 12(11):1983.doi: 10.1017/S1368980009005199 [PubMed: 19323863] 
Tamiru D, Belachew T, Loha E, Mohammed S. Sub-optimal breastfeeding of infants during the first six months and associated factors in rural communities of Jimma Arjo Woreda, Southwest Ethiopia. BMC Public Health. 2012; 12(1):363.doi: 10.1186/1471-2458-12-363 [PubMed: 22607266]

Tomlinson M, Doherty T, Ijumba P, Jackson D, Lawn J, Persson LÅ, Chopra M. Goodstart: a cluster randomised effectiveness trial of an integrated, community-based package for maternal and newborn care, with prevention of mother-to-child transmission of HIV in a South African township. Tropical Medicine \& International Health. 2014; 19(3):256-266. DOI: 10.1111/tmi. 12257 [PubMed: 24433230]

Victor R, Baines SK, Agho KE, Dibley MJ. Determinants of breastfeeding indicators among children less than 24 months of age in Tanzania: a secondary analysis of the 2010 Tanzania Demographic and Health Survey. BMJ Open. 2013; 3(1)doi: 10.1136/bmjopen-2012-001529

Victora CG, Horta BL, Loret de Mola C, Quevedo L, Pinheiro RT, Gigante DP, Barros FC. Association between breastfeeding and intelligence, educational attainment, and income at 30 years of age: a prospective birth cohort study from Brazil. The Lancet. Global Health. 2015; 3(4):e199-205. DOI: 10.1016/S2214-109X(15)70002-1 [PubMed: 25794674]

Volmink J, Marais B. HIV and AIDS. Lancet. 2008. Retrieved from http://www.researchgate.net/ profile/Ben_Marais/publication/24435179_HIV_mother-to-child_transmission/links/ 00b7d5224146b04378000000.pdf

Willig C, Stainton-Rogers W. The SAGE Handbook of Qualitative Research in Psychology The sage handbook of qualitative research in psychology. 1 Oliver's Yard, 55 City Road, London EC1Y 1SP United Kingdom: SAGE Publications Ltd.; 2007. Introduction; 1-12.

World Health Organization. Guidelines on HIV and infant feeding 2010 Principles and recommendations for infant feeding in the context of HIV and a summary of evidence. Geneva: World Health Organization; 2010. Retrieved from http://www.who.int/maternal_child_adolescent/ documents/9789241599535/en/\#.Vd2-ItzJejQ.mendeley

World Health Organization. WHO | Infant and young child feeding. 2015. Retrieved from http:// www.who.int/mediacentre/factsheets/fs342/en/ 


\section{Significance}

Evidence from large prospective studies conducted in sub-Saharan Africa have shown a two- to 11-fold reduction in MTCT among HIV-infected women who exclusively breastfeed compared to those who mix-feed (Coovadia et al., 2007; Coutsoudis, Pillay, Spooner, Kuhn, \& Coovadia, 1999; Iliff et al., 2005; Kuhn et al., 2007). Long-term benefits of breastfeeding include a reduction in infant morbidity and mortality (Ip et al., 2007), improved growth and development of the child, and improved cognitive development and scholastic achievement (Horta \& Victora, 2013; Kramer et al., 2008; Lucas, Morley, Cole, Lister, \& Leeson-Payne, 1992; Victora et al., 2015). Despite these benefits, various factors prevent both HIV-infected and uninfected women from adhering to EBF practices. These results suggest that barriers to EBF include physiological issues (such as nipple pain) and employment, and facilitators such as social and financial support. 


\section{Table 1}

Sample characteristics

\begin{tabular}{lcc}
\hline & $\begin{array}{c}\text { HIV infected } \\
(\mathbf{n}=\mathbf{2 5})\end{array}$ & $\begin{array}{c}\text { HIV uninfected } \\
(\mathbf{N}=\mathbf{1 2})\end{array}$ \\
\hline Age (median) & 33 & 30 \\
Number of previous pregnancies & & \\
1 & 6 & 4 \\
2 & 9 & 4 \\
3 & 5 & 0 \\
4 & 2 & 3 \\
5 & 2 & 0 \\
6 & 1 & 0 \\
7 & 0 & 1
\end{tabular}

Education

\begin{tabular}{|c|c|c|c|}
\hline & None & 1 & \\
\hline Elementa & $\mathrm{y} /$ Junior & 7 & 2 \\
\hline Secondary $/ \mathrm{Hi}$ & h school & 10 & \\
\hline Higher $\mathrm{E}$ & ducation & 7 & 10 \\
\hline & $\begin{array}{l}\text { HIV infected } \\
\quad(n=25)\end{array}$ & $\begin{array}{l}\text { HIV uninfected } \\
(\mathbf{N}=12)\end{array}$ & \\
\hline Occupation & & & \\
\hline Housewife & 8 & 2 & \\
\hline Salaried (government) & 3 & 1 & \\
\hline Student; Other & & 1 & \\
\hline Marital status & & & \\
\hline Single & 1 & 0 & \\
\hline Married & 23 & 12 & \\
\hline Widowed & 1 & 0 & \\
\hline Electricity (yes) & 24 & 10 & \\
\hline Refrigerator (yes) & 11 & 9 & \\
\hline Running water (yes) & 7 & 5 & \\
\hline
\end{tabular}




\section{Table 2}

Results from the thematic analysis

\begin{tabular}{|c|c|c|}
\hline \multicolumn{2}{|c|}{ Advice on infant feeding method } & Clinic \\
\hline & & Husbands \\
\hline & & Family/ friends \\
\hline \multirow{3}{*}{\multicolumn{2}{|c|}{ Decision influencer }} & Own knowledge and beliefs about EBF \\
\hline & & Improved growth and intelligence of child \\
\hline & & Infant won't fall ill easily \\
\hline \multirow{4}{*}{\multicolumn{2}{|c|}{ Barriers to EBF }} & Physiological problems (nipple pain, not enough milk, and teething) \\
\hline & & Employment \\
\hline & & Time consuming \\
\hline & & Food insecurity \\
\hline \multirow{2}{*}{\multicolumn{2}{|c|}{ Facilitators of EBF }} & Affordable \\
\hline & & Taking infant with to place of employment \\
\hline \multirow{2}{*}{\multicolumn{2}{|c|}{ Barriers to FF }} & Perceived stigma \\
\hline & & Unhygienic practices, Expensive \\
\hline Facilitators of FF & \multicolumn{2}{|c|}{ Flexibility for a working mother } \\
\hline \multirow[t]{5}{*}{ Cultural beliefs } & \multicolumn{2}{|c|}{ Infants need water } \\
\hline & \multicolumn{2}{|l|}{ Tradition } \\
\hline & \multicolumn{2}{|c|}{ Wash the breast before breastfeeding } \\
\hline & \multicolumn{2}{|c|}{ Religious privilege } \\
\hline & \multicolumn{2}{|c|}{ If you are HIV infected your breast milk is not good } \\
\hline \multirow[t]{2}{*}{ Support structures } & \multicolumn{2}{|l|}{ Husband } \\
\hline & \multicolumn{2}{|c|}{ Mothers and/or sisters } \\
\hline
\end{tabular}

